\title{
How I Know (Knew)
}

\author{
Kaitlyn Krahe
}

Amidst the chaos of our reality, Where smoke and mirrors,

And schemes and elaborate facades,

As sordid mud soils even the clearest lake, Obscures truth and thus,

Greatly limits the number of things of which I can be positively certain,

It is hard to say that one really knows much.

But the way the corners of your mouth tug,

Damp with saliva from lying on your side,

Like marionettes coerced gently by a twitch of their strings,

Your eyes still closed, drunk and welded shut with the

Sandman's liquor,

Upward into a smile,

When I press my lips onto yours at $4 \mathrm{am}$.

It is not a show-off-y kind of smile,

Baring teeth and paired with the sorts of eyes that make

their socket's knot, wrinkle and sag. No,

It is quiet, secret, subtle,

It is happy.

And it is then I know,

Highlighted in the effervescent glow of the milky way,

That you love me. 